\title{
Delivering health interventions to women, children, and adolescents in conflict settings: What have we learned from 10 country case studies?
}

Neha S. Singh $\mathrm{PhD}^{1}$, Anushka Ataullahjan ${ }^{2} \mathrm{PhD}$, Khadidiatou Ndiaye $\mathrm{PhD}^{3}$, Jai K. Das ${ }^{4}$, Prof. Paul H.Wise $\mathrm{PhD}^{5}$, Chiara Altare $\mathrm{PhD}^{6}$, Zahra Ahmed MSc ${ }^{7}$, Samira Sami $\mathrm{PhD}^{6,8}$, Chaza Akik DrPH ${ }^{9}$, Hannah Tappis DrPH ${ }^{6}$, Shafiq Mirzazada MPH ${ }^{10}$, Prof. Isabel C. GarcésPalacio DrPH ${ }^{11}$, Hala Ghattas $\mathrm{PhD}^{9}$, Prof. Ana Langer $\mathrm{MD}^{12}$, Prof. Ronald J. Waldman ${ }^{13,14}$, Prof. Paul Spiegel $\mathrm{PhD}^{6}$, Prof. Zulfiqar A. Bhutta $\mathrm{PhD}^{2,4}$, Prof. Karl Blanchet $\mathrm{PhD}^{1,15^{*}}$, and the BRANCH steering committee

${ }^{1}$ Health in Humanitarian Crises Centre, London School of Hygiene and Tropical Medicine, London, United Kingdom

${ }^{2}$ Center for Global Child Health, Hospital for Sick Children, Toronto, Canada

${ }^{3}$ Milken Institute School of Public Health, George Washington University, Washington, DC, USA

${ }^{4}$ Center of Excellence in Women and Child Health, The Aga Khan University, Karachi, Pakistan

${ }^{5}$ Department of Pediatrics, Stanford University School of Medicine, Stanford, California, USA

${ }^{6}$ Department of International Health, Johns Hopkins Bloomberg School of Public Health, Baltimore, Maryland, USA

${ }^{7}$ Somali Disaster Resilience Institute, Mogadishu, Somalia

${ }^{8}$ CDC National Center for HIV/AIDS, Viral Hepatitis, STD, and TB Prevention

Division of HIV/AIDS Prevention, Atlanta, Georgia, USA

${ }^{9}$ Center for Research on Population and Health, Faculty of Health Sciences, American University of Beirut, Beirut, Lebanon

${ }^{10}$ Aga Khan University, Kabul, Afghanistan

${ }^{11}$ Epidemiology group, School of Public Health, Universidad de Antioquia, Medellín, Colombia

${ }^{12}$ Women and Health Initiative; Department of Global Health and Population, Harvard T.H. Chan School of Public Health, Boston, Massachusetts, USA

${ }^{13}$ Doctors of the World USA, 222 Broadway, 19th Floor, New York, NY 10038, USA

${ }^{14}$ Global Health Department, Milken Institute School of Public Health, George Washington University, 950 New Hampshire Ave. NW 4th Floor, Washington, DC 20052, USA.

15 The Geneva Centre of Humanitarian Studies, University of Geneva, Graduate Institute, Geneva 1211, Switzerland

\section{*Corresponding author:}

Karl Blanchet, PhD; Address: The Geneva Centre of Humanitarian Studies, University of Geneva, Graduate Institute, Geneva 1211, Switzerland; Email: karl.blanchet@,unige.ch

Word count: 4467 


\section{Summary}

Armed conflict disproportionately affects women, newborns, children, and adolescents. Our study presents insights from a collection of ten country case studies aiming to assess the provision of sexual, reproductive, maternal, newborn, child and adolescent health and nutrition (abbreviated to women's and childern's health, i.e WCH in this paper) interventions in conflict-affected settings in Afghanistan, Colombia, Democratic Republic of Congo, Mali, Nigeria, Pakistan, Somalia, South Sudan, Syria and Yemen. We found that despite large variations in contexts and decision-making processes, antenatal care, basic emergency obstetric and newborn care (BEmONC), comprehensive emergency obstetric and newborn care (CEmONC), immunisation, treatment of common childhood illnesses, infant and young child feeding (IYCF) and malnutrition treatment and screening were prioritised in these ten conflict settings. Many lifesaving WCH services, including the majority of reproductive, newborn and adolescent health services, are not reported as being delivered in the ten conflict settings, and interventions to address stillbirths are absent. International donors remain the primary drivers of influencing the what, where, and how of implementing $\mathrm{WCH}$ interventions. Interpretation of WCH outcomes in conflict settings are particularly contextdependent given the myriad of complex factors that constitute conflict and their interactions. Morevoer, the comprehensiveness and quality of data remain limited in conflict settings. The dynamic nature of modern conflict and the expanding role of Non-State Armed groups in large geographic areas pose new challenges to delivering WCH services. However, the humanitarian system is creative and pluralistic and has developed some novel solutions to bring lifesaving WCH services closer to populations using new modes of delivery. These solutions, when rigorously evaluated, can represent concrete response to current implementation challenges to modern armed conflicts. 


\section{Key messages}

1. Many lifesaving women's and children's health (WCH) services for key populations in conflict settings are not delivered everywhere.

2. Priorities of donors are the primary drivers of influencing the what, where, and how of implementing WCH interventions

3. Priority predefined packages of WCH services are not commonly agreed on and implemented in conflict settings.

4. Working within the political and governance systems in conflict settings is increasingly challenging compared to previous decades, given the dynamic nature of modern conflict and the expanding role of Non State Armed groups.

5. The humanitarian system is creative and has developed new solutions to bring lifesaving WCH services closer to populations in very challenging environments.

6. Recognising and valuing the primary role of local actors would improve timely and appropriate $\mathrm{WCH}$ care delivery.

\section{Introduction}

Armed conflicts have disastrous effects on civilian populations. It is estimated that more than half a million civilians have been killed by combat operations in Syria alone between 2011 and 2019, ${ }^{2}$ a significant number of whom were civilians (1126230) and amongst them women (13173 casualties), children and adolescents (21605 casualties under the age of 18). The toll from the extended, indirect effects of conflict due to the destruction of food supplies, roads, electricity and water infrastructure, and health facilities has also been catastrophic., In 2017, 701 attacks were reported on health facilities, health care staff, patients and ambulances in 23 conflict-affected countries. ${ }^{5}$ Armed conflicts have also negatively affected the number of forcibly displaced people in the world, increasing each year in the last decade, with 70.8 million people displaced by December $2018 .{ }^{6}$ New estimates from Bendavid et al. in this Series of the number of women and children affected by conflict - at least 630 million in 2017, including over 50 million women and children displaced by conflict - is, at over $8 \%$ of the world's population, strikingly large. ${ }^{7,8}$ This paper complements other Series papers by presenting empirical insights from a collection of ten country case studies aiming to assess the provision of WCH services in contemporary conflicts in Afghanistan, Colombia, Democratic Republic of Congo (DRC), Mali, Nigeria, Pakistan, Somalia, South Sudan, Syria and Yemen.

2 The key research question asked today is whether traditional humanitarian assistance has had

3 a positive effect on saving lives and mitigating morbidity and mortality in modern armed

4 conflicts. The implicit question is whether the humanitarian community has been able to

5 adapt to the changing nature of armed conflicts and respond to women's, children's and

6 adolescents' health needs.

8 Country case study teams comprised of local and international research partners often

9 supported by relief agencies. Their work was guided by a common research protocol (Panel

10 1), ${ }^{1}$ with desk review parameters, quantitative analysis of national datasets (when available), 
11 primary qualitative data collection tools and fieldwork strategies adapted to examine factors influencing planning and implementation of WCH services in each setting. Detailed results from each country are published elsewhere. ${ }^{1}$ The present paper presents the synthesised results and implications from the analysis of the ten country case studies.

\section{Panel 1. Case study selection criteria and methodology}

This Series paper presents insights from a collection of ten country case studies aiming to assess the provision of women's and childern's health (WCH) services in contemporary conflicts in Afghanistan, Colombia, Democratic Republic of Congo (DRC), Mali, Nigeria, Pakistan, Somalia, South Sudan, Syria and Yemen. Countries were selected to ensure representation across geographies and conflict stages (e.g. acute, protracted, post-conflict).

Country case study teams comprised of local and international research partners often supported by humanitarian agencies. The teams' work was guided by a common research protocol, ${ }^{1}$ with desk review parameters, quantitative analysis of national datasets (where available), primary qualitative data collection tools and fieldwork strategies adapted to examine factors influencing planning and implementation of $\mathrm{WCH}$ services in each setting..

We used a framework analysis approach to describe the coverage and spectrum of WCH interventions delivered, and to assess explanatory variables affecting variation in health service delivery. Our analysis focused on decision-making processes, obstacles to implementation of proven WCH interventions, and adaptation of service delivery strategies to address health needs of women, newborns, children and adolescents in varied geographic, political, economic and environmental conditions.

\section{Social determinants affecting the health of women, newborns, children and adolescents}

The effects of armed conflict are the combination of a number of risks factors including the nature and exposure to conflict, the social determinants of health and the level of risks and vulnerabilities experienced by women, newborns, children and adolescents. The social determinants affecting their health in conflict settings include: lack of safe water and sanitation; poor quality housing; poor nutrition; and lack of timely access to quality health services; which in turn influence the health, opportunities for social and intellectual development and quality of life of children and newborns even more, as they grow up in an environment in which their ability to exercise their basic rights have deteriorated due to immediate threats to security during occupation, fighting, etc.; experience of traumatic events; and lack of opportunity to play as a way of developing social and motor skills. Additionally, conflict and its attendant trauma often require that women undertake new social and economic roles. Alternatively, women may become more vulnerable, if they are isolated and exposed to violence and lack of resources. Women and adolescent girls are more commonly exposed to sexual and gender-based violence including rape, which is often used as a weapon of war. 
The nature of contemporary armed conflicts: analysing security attributes of the ten case study countries

Humanitarian actors are confronted today by increasingly complex armed conficts. As analysed by Wise et al. in this Series, ${ }^{9}$ each conflict possesses its own unique character and history, and the impact of each conflict on civilian populations is rooted in complex political, strategic, and military determinants. Derived and expanded from the conceptual framework presented in Wise et.al, ${ }^{9}$ Table 1 presents selected attributes of the case study conflicts related to the nature of warfare and the strategies and tactics of the engaged state and non-

43 state combatant groups.

All the country case study conflicts are both intra-state, often labelled "civil" wars, and also internationalised, inter-state wars or conflict initiated by Non State Armed Groups (NSAGs) operating internationally. While most of the studied conflict settings are primarily rural in nature, Syria and Yemen have experienced destructive urban sieges, with the large-scale use of high explosives, including from airstrikes and artillery, in densely populated areas. ${ }^{10,11}$ It is challenging to summarise the organisational structure, strategies and tactics utilised by the various combatant groups, as the number of these groups are large and vary over time. However, it is useful to distinguish generally between the strategic attempts of belligerents to gain political legitimacy among civilian populations or to coerce civilian compliance through direct attacks or the deprivation of essentials of life or access to humanitarian assistance, and more specifically to essential WCH services.

In all ten countries where the conflict is characterised by a multitude of NSAGs, the access to populations that humanitarian actors have achieved has mostly been a result of humanitarian negotiations with parties to the conflict. Faced with increasingly complex dynamics in armed conflict as shown in Table 1 below, humanitarian actors have increased investments in 
62 Table 1. Case study country classification according to attributes of conflict

\begin{tabular}{|c|c|c|c|c|c|}
\hline & $\begin{array}{l}\text { Conflict } \\
\text { setting* }\end{array}$ & $\begin{array}{l}\text { Total } \\
\text { Population } \\
\text { (World Bank, } \\
\mathbf{2 0 1 8}^{13} \text { ) }\end{array}$ & $\begin{array}{l}\text { Population in } \\
\text { need of } \\
\text { humanitarian } \\
\text { assistance } \\
(\text { OCHA, 2020 } \\
14)\end{array}$ & $\begin{array}{l}\text { Battle-related } \\
\text { deaths 1989-2018 } \\
\text { (Uppsala Conflict } \\
\text { Data Program) }\end{array}$ & Combatants: Number of Non State Armed Groups 9 \\
\hline Afghanistan & Rural/Urban & 37.2 million & 9.4 million & 227,510 & $\begin{array}{l}8+ \\
\text { Main parties include Afghan Armed Forces, North Atlantic Treaty Organization } \\
\text { (NATO) Resolute Support, US Forces Afghanistan, Taliban; also have Al Qaeda, } \\
\text { Islamic State of Iraq and Syria (ISIS), Haqqani network, militia groups }\end{array}$ \\
\hline Colombia & Rural & 49.6 million & 5.1 million & 27,617 & $\begin{array}{l}8+ \\
\text { Main parties include Colombian military, Fuerzas Armadas Revolucionarias de } \\
\text { Colombia (FARC), Ejército de Liberación Nacional (ELN); and Autodefensas } \\
\text { Gaitanistas de Colombia (AGC), Rastrojos, Aguilas Negras, Puntilleros, Ejército } \\
\text { Popular de Liberación (EPL) }\end{array}$ \\
\hline $\begin{array}{l}\text { Democratic } \\
\text { Republic of } \\
\text { Congo }\end{array}$ & Rural & 84.1 million & 15.9 million & 112,327 & $\begin{array}{l}100+ \\
\text { Main parties are Forces Armées de la République Démocratique du Congo } \\
\text { (FARDC), Mouvement du } 23 \text { mars (M23), Forces démocratiques de libération du } \\
\text { Rwanda (FDLR), Union pour la Réhabilitation de la Démocratie du Congo } \\
\text { (URDC), Mission de l'Organisation des Nations Unies pour la stabilisation en } \\
\text { République démocratique du Congo (MONUSCO), Nduma défense du Congo- } \\
\text { Rénové (NDC-R), Union Paysanne pour le Développement Intégral (UPDI), } \\
\text { Forces démocratiques alliées/National Army for the Liberation of Uganda } \\
\text { (ADF/NALU), Lord's Resistance Army (LRA), Forces nationales de liberation } \\
\text { (FNL), Alliance des patriotes pour un Congo libre et souverain (ALPCS) } \\
\text { Kamuina Nsapu, Bana Mura, Mai Mai Mazembe, Force de résistance patriotique } \\
\text { d'Ituri (FRPI), other Mai Mai militias and ethnic factions, and Burundian } \\
\text { antigovernment militias. }\end{array}$ \\
\hline Mali & Rural & $\begin{array}{l}19.1 \\
\text { Million }\end{array}$ & 3.6 million & 5,886 & $\begin{array}{l}10+ \\
\text { Main parties are Military of Mali, African-led International Support Mission to } \\
\text { Mali (AFISMA), Mouvement National pour la Libération de l'Azawad (MNLA), } \\
\text { Ganda Iso, Front de libération nationale de l'Azawad (FLNA), Mouvement pour }\end{array}$ \\
\hline
\end{tabular}




\begin{tabular}{|c|c|c|c|c|c|}
\hline & & & & & $\begin{array}{l}\text { le salut de l'Azawad (MSA), Groupe d'Autodéfense Tuareg Imghad et Alliés } \\
\text { (GATIA), Al-Qaeda in the Islamic Maghreb (AQIM), ISIS, Boko Haram }\end{array}$ \\
\hline Nigeria & Rural & 195.9 million & $\begin{array}{l}7.7 \text { million }+ \\
284,843 \text { refugees } \\
\text { in region }\end{array}$ & 54,538 & $\begin{array}{l}12+ \\
\text { Main parties include Northeast actors: Nigerian military, Multinational Joint Task } \\
\text { Force (MNJTF), Civilian Joint Task Force (CJTF), Boko Haram, ISIS West } \\
\text { Africa, hunters, dan banga, other militias, AQIM; Middle Belt: Fulani and Hausa } \\
\text { herders, Tiv and Tarok farmers }\end{array}$ \\
\hline Pakistan & Rural/Urban & 212.2 million & 2.9 million & 41,562 & $\begin{array}{l}\text { 14+ } \\
\text { Main parties are Pakistani military/Inter-Services Intelligence (ISI), } \\
\text { TalibanHaqqani network, al Qaeda, Lashkar-e-Taiba, } \\
\text { Balochistan Liberation Army (BLA), Harkat-ul-Jihad al-Islami, Jaish-e- } \\
\text { Mohammed, Hizbul Mujahideen, Harkat-ul-Mujahideen, Al-Badr, Islamic State } \\
\text { of Iraq and the Levant - Khorasan Province (ISIL-KP), Islamic Movement of } \\
\text { Uzbekistan, other Sunni militant factions }\end{array}$ \\
\hline Somalia & Rural & 15 million & 5.2 million & 48,009 & $\begin{array}{l}7+ \\
\text { Main parties are Somali armed forces, Al-Shabaab, } \\
\text { African Union Mission to Somalia (AMISOM), Kenyan troops, United States } \\
\text { (US) counterterror operations, ISIS, Al Qaeda }\end{array}$ \\
\hline South Sudan & Rural & 10.9 million & $\begin{array}{l}7.5 \text { million }+2.3 \\
\text { million refugees } \\
\text { in region }\end{array}$ & 11,104 & $\begin{array}{l}40+ \\
\text { Main parties are Sudan People's Liberation Army (SPLA), United Nations } \\
\text { Mission in South Sudan (UNMISS), Mathiang Anyoor, Maban Defence Force, } \\
\text { outh Sudan Liberation Movement (SSLM), Justice and Equality Movement } \\
\text { (JEM), Sudan People's Liberation Movement-North (SPLM-N), } \\
\text { Ethiopian Unity Patriots Front (EUPF), } \\
\text { Sudan People's Liberation Movement-in-Opposition (SPLM-IO), Nuer White } \\
\text { Army, and many others as it is estimated that South Sudan has at least } 40 \text { armed } \\
\text { groups. }^{15}\end{array}$ \\
\hline Syria & Urban & 16.9 million & $\begin{array}{l}11 \text { million }+5.6 \\
\text { million refugees } \\
\text { in region }\end{array}$ & 345,079 & $\begin{array}{l}15+ \\
\text { Main parties are Syrian Arab Army, Russia, National Defense Force, Shabiha, } \\
\text { Foreign Shia militias inluding Hezbollah, Free Syrian Army, Jabhat Tahrir } \\
\text { Souriya, ISIS, Hayat Tahrir al-Sham (formerly Nusra), US-led coalition, Syrian } \\
\text { Democratic Forces, People's Protection Units (YPG), Turkey, Israel }\end{array}$ \\
\hline Yemen & Urban & 28.5 million & 24 million & 26,230 & $11+$ \\
\hline
\end{tabular}




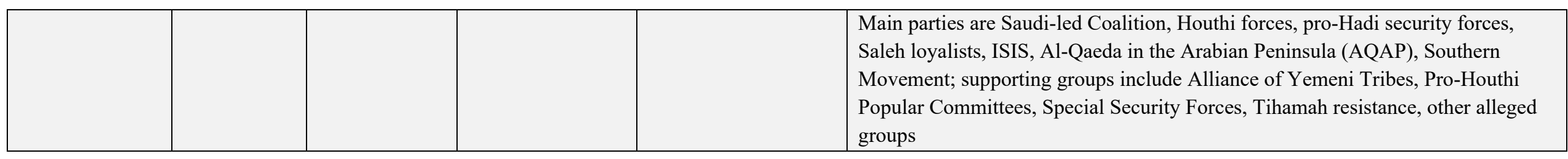

64 *Legend:

65 Rural = conflict setting is primarily rural in nature

66 Urban $=$ conflict setting is primarily urban in nature 
68 Our analyses found no clear patterns on WCH intervention delivery in conflict settings. In

69 Afghanistan and Pakistan, our analysis suggested a statistically significant difference in coverage of various WCH interventions between severely/moderately and minimally conflict-affected provinces/districts based on the battle-related deaths. ${ }^{16,17}$ In Colombia, maternal mortality, antenatal care coverage, caesarean section rate, and fertility in 15 to 19 year-old adolescents were significantly different in municipalities with high versus low levels of conflict (measured as victimisation rates), and no statistically significant difference was found in vaccination coverage, neonatal, early neonatal and infant mortality rates between high and low conflict quintiles. ${ }^{18}$ In Nigeria, although there were differences in various indicators including vaccination coverage and neonatal and child mortality among the conflict-affected, marginal and stable (non-conflict) areas, these differences were not statistically significant. In DRC, insecurity (measured as conflict-related fatality rate) had a significant effect on maternal death and stillbirth rates, while the impact on coverage of

In many cases, health services may exist on paper but have ceased to be delivered to people in the specified catchment area. For example, in Afghanistan, comprehensive emergency obstetric and newborn care $(\mathrm{CEmONC})$ is largely not delivered in most provinces. Similarly, the introduction of user fees at public and private health facilities has become standard practice, as has been seen in Afghanistan (at tertiary level) and southern Sudan. An overriding concern in Yemen and Syria has been how to evacuate victims of violence from the site of an incident to the nearest emergency medical centre, an issue that was regularly raised in the media because of its huge humanitarian, social and political dimension (personal communication). Health systems in conflict settings can, as in "normal" situations, support a healthy life, or, by their absence or ineffectiveness, undermine it and perpetuate health inequity.

Data from the case study countries show that the presence of armed conflict has attracted the attention, and even the intervention, of the international community, with evidence of mitigation of the adverse health impact of conflicts and sometimes even greater health and healthcare improvements that lead to important improvements in population health beyond the pre-crisis levels (e.g. DRC, Nigeria, Somalia, South Sudan). ${ }^{19-21}$ Thanks to the humanitarian system, many maternal and child health and nutrition services are now offered to a majority of those who can be reached in conflict settings.

\section{Pre-conflict capacity of health systems as a determinant of WCH priorities}

There were differences among countries in terms of what services were delivered and how. These differences can be attributed both to the intensity and nature of the conflict (e.g. whether active, protracted, cyclical) and the capacity of the health system prior to the conflict. For example, Syria was a middle-income country prior to the conflict with a functioning health system providing free-at-the-point-of-delivery primary health care services. Participants in our study reported that during the war, there were certain gaps in WCH service availability over time and by geographical locations. In areas where the health 
111 system was affected the most by the conflict, there was a delay in re-establishing WCH

112 service delivery. Prior to the conflict, Colombia also had all the infrastructures in place to

113 deliver WCH services, which were all delivered even during the conflict. Since the conflict in

114 Colombia spanned about 50 years, the capacity of its health system (e.g. infrastructure and

115 personnel) was in part developed in the midst of the conflict. All the other case study

116 countries reported long standing limitations in their health system capacity, at minimum in

117 the area where the conflict was occurring and experienced a state of protracted conflict,

118 which limited the reconstruction of capacities of these countries to deliver the wide spectrum

119 of WCH interventions.

121 The period of armed conflict that we studied cannot be disconnected from either the status antebellum or from what comes (or is to come) after. In situations like Syria, the destruction caused by armed conflict devastated the ability of whichever authorities are in charge to maintain the health status of the population at a high level. However, in some case study countries (e.g. Nigeria, Somalia), the situation was very different prior to the eruption of conflict. In Nigeria, for example, it would be difficult to claim that the exacerbation of conflict in the Northeast in 2009 had a major impact on routine health service delivery when the 2008 Demographic Health Survey recorded a vaccination coverage in Borno State of 8\%, which is far below the national average. ${ }^{22}$ Morever, there are countries where central

130 Governments have been purposely neglecting the conflict-affected parts of the country, e.g. the weaknesses in Nigeria may, in fact, contribute to some causes for the origin of the conflict. Weak health systems in conflict-affected parts of the country are not just "innocent bystanders," but rather a symptom of longstanding prejudicial policies. This might not be the case in Syria, where the national health system was generally strong, but in countries like Mali, Nigeria and Afghanistan there has been longstanding neglect, which leads to a situation where, with intervention from the humanitarian community, it is possible that the health status of the population will counter-intuitively improve during the conflict, only to deteriorate once again when there is either peace or when the humanitarian community is no longer providing assistance at the same level.

\section{Prioritising among WCH interventions: who decides?}

143 As it stands, the prioritisation of WCH interventions is not very clear. Priority in all the case study settings is given to a set of specific interventions: antenatal care, BEmONC and CEmONC for pregnant women and immediate care for newborns; childhood immunisation, treatment of common childhood illnesses, infant and young child feeding (IYCF) and malnutrition screening and treatment through in-patient, outpatient and stabilisation centres, as these were considered life-saving interventions. Immunisation is a clear priority in humanitarian response albeit implementation barriers vary across case study settings, including limited humanitarian access to populations, lack of infrastructure for cold chain maintenance and community reluctance. In Afghanistan and Pakistan, we also found a specific focus on polio campaigns, which has been prioritised due to funding opportunities rather than based on life saving gounds. 
155 On the other hand, there is a set of interventions that is neglected in most countries: abortion

156 and post-abortion care, as well as provision of contraception were not prioritised by the

157 implementing stakeholders, particularly in countries where religious and cultural practises

158 affected the acceptability of such services like in Afghanistan, Mali, Nigeria, Pakistan,

159 Somalia and Yemen. Policy and political environments also influenced the provision of these

160 services, e.g. in Colombia, family planning interventions were mainly restricted to urban

161 areas, whereas DRC continues to enforce a law that prohibits the sale and use of

162 contraceptive methods for young people and adolescents. Adolescent health was also another

163 area that was alarmingly largely ignored, with the majority of the case studies reporting no

164 evidence of such implementation, with the exception of international humanitarian

165

166 organisations-led reproductive health programmes - although with a very limted scope - for

167 adolescents in DRC and Somalia.

Ten years ago, the call from Hurst et al. for "accountability for reasonableness" in the humanitarian sector ${ }^{23}$ has not been fully heard. What we observed in the ten countries is that decisions are rather the fruit of a negotiation process between the international organisations and the national authorities but also between the humanitarian organisations themselves. Beyond the politics of humanitarian aid, the driver for interventional implementation remains the access to the right resources: financial resources from international donors and expertise from national and international organisations. Respondents in most country case study settings described that the priorities of donors are the primary drivers of influencing the what, where, and how of implementing interventions. Although the central government in some countries (e.g. Colombia, Nigeria, and Afghanistan) is more actively involved in managing and overseeing services, often the involvement in healthcare delivery of government officials shrinks as conflict escalates in terms of scale and intensity. We found that decisions and the ability to implement humanitarian WCH interventions are not uniquely based on needs assessments and security situation, but also on the availability of local and international actors on the ground who can rapidly deploy, access population groups and monitor the quality and coverage of $\mathrm{WCH}$ interventions. Going forward, a rational prioritization process in conflict settings could follow the logic of determining the epidemiological burden of the problem that the intervention seeks to allay; a consideration of the available cost-effective interventions and actors to address those problems with a high epidemiological burden; and a consideration of the context, including security risks encountered by communities to get access to health services and health care workers to deliver health care, cultural factors, the capacities of the health system, and issues outside of the health sector that might be of higher priority than health sector issues. For example, this process was followed in 2019 in Afghanistan to develop its Integrated Package of Essential Health Services. ${ }^{24}$

To bring clarity to the situation, we have identified the existence of four different but not mutually exclusive models of decision-making amongst governmental and humanitarian actors, which all dictate the mode of relationship and operation (Table 2).

Table 2. Models of decision-making amongst humanitarian and governmental actors 


\begin{tabular}{|c|c|c|}
\hline $\begin{array}{l}\text { Decision-making } \\
\text { model }\end{array}$ & Description & $\begin{array}{l}\text { Examples from case } \\
\text { study countries }\end{array}$ \\
\hline Centralised & $\begin{array}{l}\text { The decision-making system on which interventions are } \\
\text { prioritised is centralised at government level and often } \\
\text { influenced by UN agencies and funders. As an } \\
\text { illustration, participants in Pakistan report stringent } \\
\text { government regulations to work in conflict areas and } \\
\text { approvals for non-governmental organisations (NGOs) } \\
\text { are particularly cumbersome, in particular to work in } \\
\text { federally administered tribal areas (FATA). }\end{array}$ & $\begin{array}{l}\text { Afghanistan, } \\
\text { Colombia, Pakistan, } \\
\text { Syria }\end{array}$ \\
\hline $\begin{array}{l}\text { Humanitarian actors- } \\
\text { led }\end{array}$ & $\begin{array}{l}\text { In some settings, UN agencies and other humanitarian } \\
\text { actors lead the choice of interventions to be implemented } \\
\text { and delivery of health services. However, we found in } \\
\text { our case studies that the decision-making process within } \\
\text { and across these UN and humanitarian agencies on which } \\
\text { interventions to prioritise was variable and not following } \\
\text { uniform guidelines. }\end{array}$ & $\begin{array}{l}\text { Somalia, South Sudan, } \\
\text { Yemen, Syria }\end{array}$ \\
\hline Collaborative & $\begin{array}{l}\text { Settings where decision-making is a collaborative } \\
\text { endeavour shared between government and humanitarian } \\
\text { actors for defining both which WCH interventions are } \\
\text { delivered, and how. These collaborative relationships are } \\
\text { not always fully balanced between actors in terms of } \\
\text { power and technical capacity }\end{array}$ & $\begin{array}{l}\text { Afghanistan, DRC, } \\
\text { Nigeria, Mali, Syria }\end{array}$ \\
\hline Gatekeeping & $\begin{array}{l}\text { This model is characterised by other conflict settings } \\
\text { where the ministry of health }(\mathrm{MoH}) \text { and Non-State } \\
\text { Armed Groups have little or no control or power over the } \\
\text { technical content of interventions, but become } \\
\text { gatekeepers to regulate who works in government and } \\
\text { rebel-controlled areas and delivers which interventions. }\end{array}$ & Yemen \\
\hline
\end{tabular}

199 The four models are not mutually exclusive and vary over time and space. For example, in the case of Syria, the decision-making model depends on which entity (i.e. government versus non-governmental authorities) has the authority to deliver health services in a specific geographic area, which is why two different models co-exist: the humanitarian actors-led model in non-government-controlled areas; and collaborative model in governmentcontrolled areas. Our findings suggest that there are ongoing tensions between humanitarian modes of delivery and national health systems.

\section{Tensions between the humanitarian system and the national health system}

208 The differences in terms of approach between different humanitarian actors or between

209 national authorities and humanitarian actors illustrate the unpredictability and uncertainty of

210 situations that require constant adaptability.

212 Many case study countries reported needing to frequently adapt their WCH interventions to

213 the escalation of insecurity in some parts of the country, the constant changes of the conflict

214 (e.g. nature, scale, movement of troops, nature and intention of belligerants) and the cost of

215 delivering WCH services in hard-to-reach locations. For example, air delivery is the only

216 means to resupply health facilities in some parts of South Sudan and Somalia. Humanitarian 
217 actors reported making adaptations to rapidly respond to and anticipate situations that are

218 often unpredictable. These adaptations included pre-establishing partnerships between UN

219 agencies and NGOs with pre-defined roles and responsibilities to respond to population

220 movements in DRC; using mobile clinics in Afghanistan to access hard-to-reach populations

221 either due to conflict and/or terrain; and donors making emergency funds available in South

222 Sudan to pre-stock medical supplies to be able to rapidly respond to outbreaks (e.g. cholera)

223 or sudden escalation in violence. These modes of operations are based on agile management

224 mechanisms, which are most often not present in public service and create differences in the

225 mode of operation between mainstream health services and humanitarian services, that

226 sometimes create tensions.

227

228 The tensions between the mainstream health system and the humanitarian system are caused

229 not only by power imbalances and unequal access to resources between international and

230 national actors, but also by differences in intervention principles. For example, in DRC, there

231 are tensions between free health care promoted by humanitarian actors clashing with the user

232 fee policy of the MOH or in Yemen where health authorities expressed frustration at times by

233 impactful decisions unilaterally made by UN agencies in terms of implementation of key

234 interventions. There is no doubt that most national authorities and humanitarian agencies

235 have a common vision of providing care to the most vulnerable. However, their time horizon,

236 budget and scale vary between humanitarian agencies targeting special geographical areas

237 and national authorities managing the national space. They also vary by country, which the

238 four models of decision-making processes have identified.

239

240 Strategies to deliver WCH services

241 Humanitarian actors (local and international) and national authorities are confronted by

242 various obstacles to deliver WCH interventions, as explained earlier. For the purpose of this

243 study, we developed health ${ }^{25}$ and humanitarian system building blocks (an adaptation of the

244 WHO health systems building blocks ${ }^{25}$ ), and classified our findings according to the

245 following domains: leadership, governance and coordination; health financing, health

246 workforce; essential medicine and supplies; health service delivery; health information

247 systems and communication; community dynamics and sociocultural factors; and security.

248 Figure 1 visualises the areas of bottleneck to delivering WCH interventions in the case study

249 countries, and Table 3 provides solutions documented in our case studies. 
Figure 1. Areas of bottleneck to implementing sexual, reproductive, maternal, newborn, child and adolescent health and nutrition 251 interventions in ten country case study settings building blocks

Health Workforce

Health Service Delivery

Security

\section{Health Financing}

Leadership, Governance, and Coordination

Community Dynamics and Sociocultural Factors

Essential Medicines and Supplies Health Information Systems and Communication

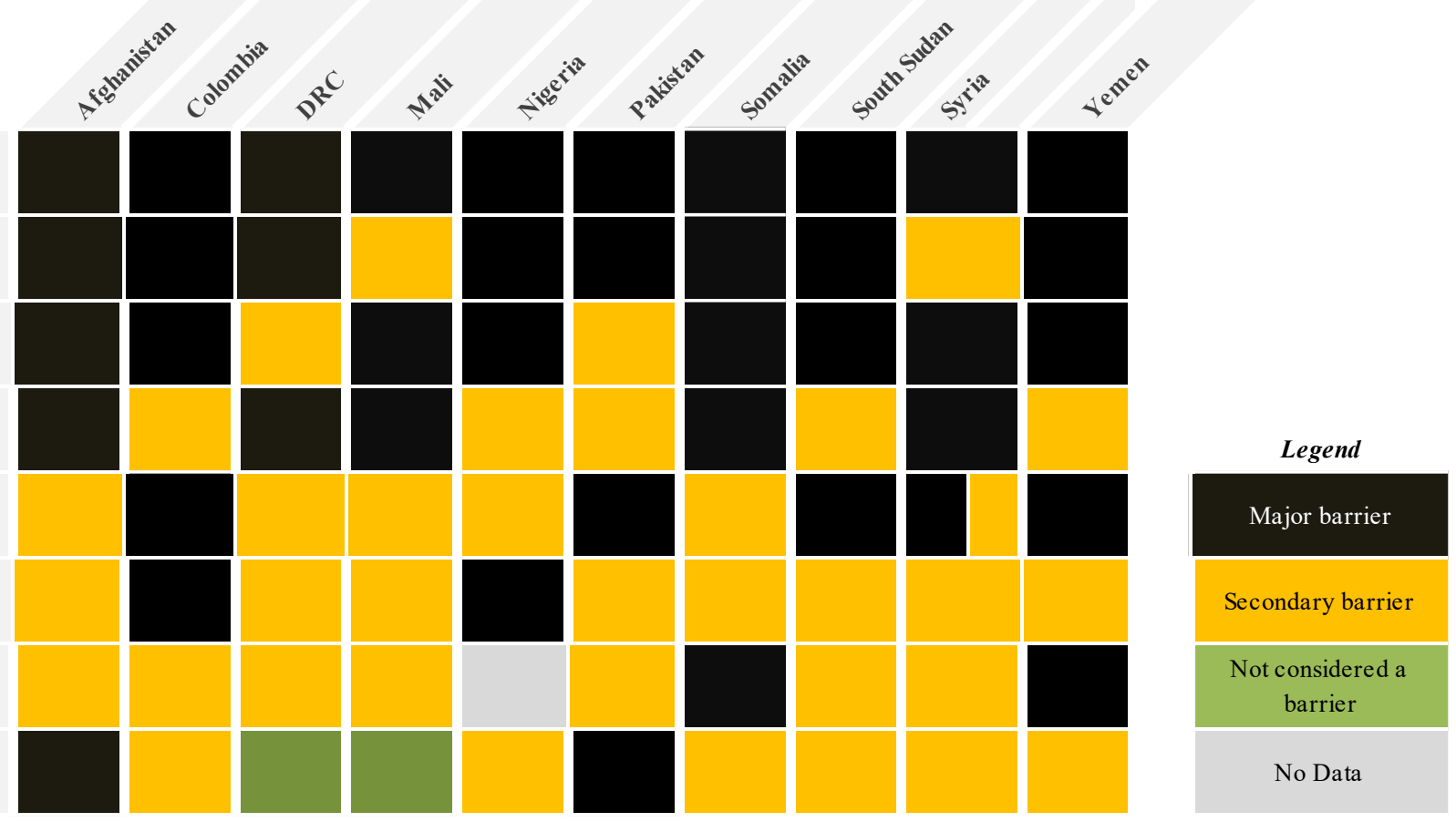


255 Cooperation between different humanitarian actors and local authorities (including government) took on a variety of forms including subcontracting to local organisations (e.g. Afghanistan, Somalia, Yemen, Mali, Syria). For example, in Syria, multiple cooperation strategies were used. Humanitarian actors worked with local NGOs while monitoring their activity through telephone calls and cross-border visits from Syrian healthcare providers to Gaziantep or Amman. Coordination between a variety of actors also led to improved data collection in some cases as well as unconventional data collection e.g. e-health, telephones and informants (e.g. Syria).

\section{The emergence of pooled funds}

Funding levels and conditions varied greatly between contexts. Unresponsive funding mechanisms, political interference in services (e.g. the Mexico City Policy or "global gag rule," which blocks United States federal funding for NGOs that provide abortion counselling or referrals, advocate to decriminalise abortion or expand abortion services), competition to get access to funding, and delays in the release of funds contributed to gaps in funding. Moreover, donors were reluctant to invest in infrastructure or operational costs (e.g. South Sudan), and multi-year programs to address the root causes of insecurity (e.g. South Sudan, governments in some countries also affected how donors distributed funds and to whom, which in many cases remains mainly concentrated in international organisations. Respondents described several mechanisms to address funding shortages and being more responsive to emergencies that included relying upon emergency pooled funds (e.g. Somalia), and other UN organizations (e.g. Yemen).

\section{Local health workforce at the forefront}

As highlighted earlier, armed conflicts are usually an exacerbating factor of existing weaknesses of national health systems but also an accelerating factor for health staff displacement. Shortages of health care workers, in particular the limited availability of health workers with certain qualifications and specific profiles (e.g. specialisation and gender) was a key problem in all contexts. Specialists such as gynaecologists, obstetricians, surgeons, paediatricians, and physiotherapists were often unavailable in most countries. Female midwives and nurses were lacking in conflict-affected areas of countries like Afghanistan, Pakistan, and Syria to enable women's access to health services. Several strategies were used to address the lack of health workers. These included increasing training programs for health staff (e.g., Somalia, Yemen, South Sudan), task shifting or task sharing (e.g. DRC, Mali, Somalia, Syria, Pakistan, Afghanistan, Yemen), and expanding the catchment area and populations for which health workers were responsible (e.g. Pakistan). In Keich district in Pakistan, for example, senior staff living centrally within the district would rotate trips to remote areas every month for a week

Local hiring and partnership with local organisations was a strategy that was employed by humanitarian agencies to address concerns surrounding health workforce, financing, and security. Local health workers, given their connection to the communities, were more likely to 
continue to work even when there were funding gaps and salary delays (e.g. Somalia,

299 Colombia). Local workforce also contributed to mitigate security threats (e.g. DRC,

300 Colombia), and their importance in communicating and establishing trust with the community

301 (e.g. Somalia, Colombia). Findings from Colombia, DRC and Somalia demonstrate the

302 importance of intrinsic motivation and a 'sense of duty' for health worker retention: national

303 health workers, particularly those who worked with children, felt a need to protect the future

304 of the country. Similarly, in South Sudan, health workers who stayed in insecure communities

305 did so out of a sense of duty to these communities.

Numerous forms of health delivery to address barriers included task shifting and taks sharing; hiring other types of health workers (e.g. community midwives, community health workers; traditional healers, traditional birth attendants); using new modes of delivery (e.g. remote management, technology such as WhatsApp or electronic clinical protocols, mobile clinics, treatment posts, home visits); implementing packages of services (e.g. sexual and reproductive health and family planning, gender-based violence centres providing delivery care) or and addressing demand for services. For example in Syria, capacity building programmes for midwives were implemented to address the population's preference for home births, in part due to reported feelings of insecurity inside hospitals which are often targeted in attacks.

\section{Rebuilding trust in the community}

319 Culturally-situated beliefs and behaviours influenced acceptance of and access to health services. The use of humanitarian assistance as a political tool can have resounding damaging effects on the community's perception of and trust in lifesaving WCH services. Specific services such as immunisation and family planning encountered religious and cultural oppositions in countries such as Pakistan, DRC, South Sudan, Nigeria and Yemen, while gender rules about female mobility limited access to care (e.g. Pakistan, Afghanistan). Moreover, the protracted nature of war and the politicisation of aid have fractured the community's trust in health service providers (e.g. in Afghanistan, DRC, Pakistan). For example, the use of polio vaccinators to identify and target Osama Bin Laden in Pakistan has created long-lasting resistance and reluctance from communities in regard to public health campaigns in both Pakistan and Afghanistan. The recruitment of local staff and use of social science methods in programmes to better understand community perceptions and expectations (e.g. the role of women in the household, the decision bearer in a family regarding child health or number of children a woman has, or the image of humanitarian organisations) and shape humanitarian interventions has been valued in countries such as Afghanistan or Pakistan.

\section{Insecurity: a key driver of WCH service delivery} Facilities' resource shortages already existing before the crisis were further exacerbated by attacks, looting and lack of investments during the crisis (e.g. Mali, South Sudan, Yemen). Vulnerable populations' access to health care are further exacerbated by breaches of medical neutrality, i.e. violations of the Fourth Geneva Convention, Article 18. Direct insecurity was a huge disincentive for working in conflict-affected areas due to the elevated risk of targeted 
threats, attacks on or kidnapping of health workers (e.g. Yemen, Afghanistan, Somalia, Syria,

343 Colombia). The insecure situation forced health care workers to put in place contingency plans (e.g. reduced movement and presence of health staff, generating patient evacuation plans, remote management). In Colombia, health personnel in some zones were trained about duties and rights of their medical mission and security plans to reduce their personal security risk. In Syria, remote management from certain hubs (e.g. a cross-border one in Gaziantep), was used to improve accessibility to certain geographic areas when no physical access was possible. ${ }^{26}$ Respondents cited the importance of local partners to provide intelligence about security threats (e.g. Mali, Colombia). Many international respondents highlighted that they relied more heavily on local and national staff and partners to deliver services (e.g. DRC, Somalia, Syria, Yemen). ${ }^{19,20,26,27}$ In some cases, insecurity necessitated the negotiation with non-state armed groups to protect their personnel (e.g. Mali, Somalia, South Sudan, Colombia). ${ }^{18,20,21,28}$ For respondents in Syria and Afghanistan, such negotiations with opposition parties allowed access to restricted geographies during a a polio campaign. ${ }^{16,26}$

Table 3. Solutions to deliver sexual, reproductive, maternal, newborn, child and adolescent helath and nutrition interventions in ten country case studies

\begin{tabular}{|c|c|}
\hline $\begin{array}{l}\text { Health and } \\
\text { humanitarian building } \\
\text { blocks }\end{array}$ & Solutions identified \\
\hline $\begin{array}{l}\text { Governance, leadership, } \\
\text { coordination }\end{array}$ & $\begin{array}{l}\text { - Political analysis on power balance between the various warring parties and } \\
\text { the various humanitarian actors } \\
\text { - Various roles taken by the Health Cluster based on level of engagement and } \\
\text { capacity of national authorities in the humanitarian response } \\
\text { - Decentralisation of operations by contracting local organisations }\end{array}$ \\
\hline Health financing & $\begin{array}{l}\text { - Creation of multi-year funding mechanisms to respond to protracted crises } \\
\text { - Creation of emergency pooled funds to respond to emergencies such as } \\
\text { outbreaks or sudden displacement of populations }\end{array}$ \\
\hline Health workforce & $\begin{array}{l}\text { - Task-shifting and task-sharing } \\
\text { - Rotation of senior staff to remote areas } \\
\text { - Hiring local staff to nuture trust with local communities and value the "sense } \\
\text { of duty" of local staff vis-à-vis their country }\end{array}$ \\
\hline $\begin{array}{l}\text { Essential medicine and } \\
\text { supplies }\end{array}$ & $\begin{array}{l}\text { - Creation of electronic stock management and supply information system to } \\
\text { automate the identification of shortage and need for resupply }\end{array}$ \\
\hline Health service delivery & $\begin{array}{l}\text { - Use of mobile clinics to deliver services to remote areas } \\
\text { - Recruitment of lay workers who have good knowledge of their community } \\
\text { - Promotion of community-based services to bring services closer to } \\
\text { populations } \\
\text { - Delivery of integrated packages of services at the point of care to avoid } \\
\text { populations to move several times }\end{array}$ \\
\hline $\begin{array}{l}\text { Community dynamics } \\
\text { and sociocultural factors }\end{array}$ & $\begin{array}{l}\text { - Social research used as way of informing how to deliver humanitarian } \\
\text { programmes }\end{array}$ \\
\hline Insecurity & $\begin{array}{l}\text { - Training of health staff on security measures } \\
\text { - Remote management } \\
\text { - Use of security intelligence to assess the situation and authorise staff } \\
\text { movement } \\
\text { - Contextually-driven negotiations with non-state armed groups (NSAGs) to } \\
\text { have access to populations and protect populations and health staff }\end{array}$ \\
\hline
\end{tabular}




\section{Conclusion}

361 Working within the political and governance systems in modern conflict settings is increasingly challenging given the dynamic nature of modern conflict and the expanding role of Non-State Armed groups who are often in control of large geographic areas, which pose new challenges to delivering services to women, children and adolescents.

Decision-making processes vary by government, organisation and context. We categorised them into four different models (centralised; humanitarian actors-led; collaborative; gatekeeping) that are not mutually exclusive. We also found that pre-conflict health system capacity, and thus readiness to respond in unpredictable events, varied greatly by case study setting. Important enabling factors included the income status of countries (e.g. middleincome versus low-income), existing infrastructure and resilience of the health system.

Despite large variations in sociocultural and geographical contexts and decision-making processes, there was consistency among prioritisation of key $\mathrm{WCH}$ interventions (i.e. antenatal care, BEmONC, CEmONC, immunisation, treatment of common childhood illnesses, IYCF and malnutrition treatment and screening) as well as the neglect of other such interventions (sexual, reproductive, newborn and adolescent health, and those for stillbirths). Given the dynamic nature of modern conflicts, proactively defining and agreeing upon an evidence-based comprehensive WCH package of interventions, taking into account existing evidence and guidelines (e.g. Inter-Agency Field Manual on Reproductive Health in Crises ${ }^{29}$, Newborn Health in Humanitarian Settings Field Guide ${ }^{30}$ ) could be an effective strategy to respond to sudden situations. The prioritisation process, in a context of scarce resources, could be an effective approach to identify the key interventions to implement and decide on the allocation of resources.

The humanitarian system is creative and has developed new solutions to bring lifesaving WCH services closer to populations by hiring and training other types of health workers, often from the affected community and using new modes of delivery. These solutions, when rigorously evaluated, can represent a concrete, timely response to current implementation challenges and remind health authorities of their responsibility to deliver basic health services to the whole population.

\section{Contributors}

394 Neha S. Singh and Karl Blanchet conceived the analysis and all authors contributed to the 395 final structure and content of the paper. Neha S. Singh and Karl Blanchet led the overall data analysis, and Anushka Ataullahjan, Zahra Ahmed, Chaza Akik, Chiara Altare, Jai K. Das, Shafiq Mirzazada, Khadidiatou Ndiaye, Samira Sami, Paul Spiegel, Hannah Tappis, and Paul H.Wise made contributions to specific sections. Neha S. Singh wrote the first draft of the paper and all authors contributed to critical interpretation of the results and development of the paper. All authors saw and approved the final version.

\section{Acknowledgments}


We would like to thank all study respondents who took part in the key informant interviews, and the BRANCH consortium members who contributed to specific country case studies: (1) Afghanistan (Wardah Ahmed, Zulfiqar A Bhutta, Jai K. Das, Malika Fatima, Zahra Feroz, Sultana Jabeen, Shafiq Mirzazada, Mohammed I. Zubair); (2) Colombia (Gladis Adriana Vélez Álvarez, Edison Bedoya Bedoya, Jewel Gausman, Isabel C. Garcés-Palacio, Sara Milena Ramos Jaraba, Marlly Andrea García Jiménez, Ana Langer, Laura Ruiz Sánchez, María Ochoa Sierra, Natalia Quiceno Toro, Ivan Dario Arroyave Zuluaga); (3) DRC (Chiara Altare, Hamady Ba, Stéphane Muzindusi Bikoro, Ghislain Bisimwa, Ties Boerma, Christopher Hook, Espoir Bwenge Malembaka, Jerome Pfaffmann, Thea Scognamiglio, Paul Spiegel, Hannah Tappis, Maphie Tosha); (4) Mali (Anushka Ataullahjan, Diego Bassani, Samba Diarra, Seydou Doumbia, Michelle F. Gaffey, Moctar Tounkara); (5) Nigeria (Eskedar Dejene, Khadidiatou Ndiaye, Ume Nwanneamaka, Chinwenwo Weli, Christina Okere, Victory Inyang, Jennifer Tyndall, Ron Waldman); (6) Pakistan (Wardah Ahmed, Zulfiqar A. Bhutta, Jai K. Das, Malika Fatima, Zahra Feroz, Sultana Jabeen); (7) Somalia (Zahra Ahmed, Anushka Ataullahjan, Abdirizak Dalmar, Michelle Gaffey, Mohamed Osman, Chantal Umutoni); (8) South Sudan (Ties Boerma, Nicole Lightman, Augustino Mayai, Wilfred Ochan, Samira Sami, Grace Sheehy, Paul Spiegel, Hannah Tappis, James Wanyama, Hannah Wild); (9) Syria (Chaza Akik, Linda Shaker Berbari, Karl Blanchet, Joanne Constantin, Jocelyn DeJong, Abdulkarim Ekzayez, Hala Ghattas, Zeina Jamaluddine, Katherine Lopes, Ghada Saad-Haddad, Aline Semaan, Neha S. Singh); and (10) Yemen (Iman Ahmed Saleh Al-Gawfi, Eman Al-Kubati, Nagiba A. Abdulghani AlShawafi, Huda BaSaleem, Sarah Elaraby, Shatha Elnakib, Fouad Othman, Nuzhat Rafique, Fouzia Shafique, Paul Spiegel, Hannah Tappis).

Funding for the country case studies was provided through a subgrant from the Centre for Global Child Health at the Hospital for Sick Children (SickKids), with travel and meeting costs supported directly by Aga Khan University and the Partnership for Maternal, Newborn and Child Health (PMNCH). As coordinator of the BRANCH Consortium (Bridging Research $\&$ Action in Conflict Settings for the Health of Women \& Children), the SickKids Centre for Global Child Health has received funding for BRANCH research activities from the International Development Research Centre (IDRC) (108416-002 \& 108640-001), the Norwegian Agency for Development Cooperation (Norad) (QZA-16/0395), the Bill \& Melinda Gates Foundation (OPP1171560), and UNICEF (PCA 20181204). Aga Khan University received funding for BRANCH activities from the Family Larsson-Rosenquist Foundation.

\section{BRANCH Consortium Steering Committee Members}

\begin{tabular}{|l|l|l|}
\hline $\begin{array}{l}\text { Author order } \\
\text { on Pubmed }\end{array}$ & First name and middle initials & Surnames \\
\hline 1 & Zulfiqar A. & Bhutta \\
\hline 2 & Robert E. & Black \\
\hline
\end{tabular}




\begin{tabular}{|l|l|l|}
\hline 3 & Karl & Blanchet \\
\hline 4 & Ties & Boerma \\
\hline 5 & Michelle F. & Gaffey \\
\hline 6 & Ana & Langer \\
\hline 7 & Paul B. & Spiegel \\
\hline 8 & Ronald J. & Waldman \\
\hline 9 & Paul H. & Wise \\
\hline
\end{tabular}

441

442

443

444

445

446

447

448

449

450

451

452

453

454

455

456

457

458

459

460

461

462

463

464

465

466

467

468

469

470

471

472

473

474

475

476

477

478

Author details:

Prof. Zulfiqar A Bhutta

Centre for Global Child Health, The Hospital for Sick Children, Toronto, Canada;

Dalla Lana School of Public Health, University of Toronto, Toronto, Canada;

Centre of Excellence in Women and Child Health, Aga Khan University, Karachi, Pakistan

Prof. Robert E Black

Department of International Health, Johns Hopkins Bloomberg School of Public Health, Baltimore, USA

Prof. Karl Blanchet

The Geneva Centre of Humanitarian Studies, University of Geneva, Graduate Institute,

Geneva, Switzerland;

Health in Humanitarian Crises Centre, London School of Hygiene and Tropical Medicine,

London, UK

Prof. Ties Boerma

Centre for Global Public Health, University of Manitoba, Winnipeg, Canada

Michelle F Gaffey

Centre for Global Child Health, The Hospital for Sick Children, Toronto, Canada;

Dalla Lana School of Public Health, University of Toronto, Toronto, Canada

Prof. Ana Langer

Women and Health Initiative; Department of Global Health and Population, Harvard T.H.

Chan School of Public Health, Boston, Massachusetts, USA

Prof. Paul B Spiegel

Center for Humanitarian Health, Johns Hopkins University, Baltimore, USA

Prof. Ronald J Waldman

Milken Institute School of Public Health, George Washington University, Washington, DC,

USA;

Doctors of the World USA, New York, NY, USA

Prof. Paul H Wise

Department of Pediatrics, Stanford University School of Medicine, Stanford, California, USA 
480 1. Ataullahjan A, Gaffey MF, Sami S, et al. Investigating the delivery of health and 481 nutrition interventions for women and children in conflict settings: a collection of case studies 482 from the BRANCH Consortium. Conflict and Health 2020; 14(1): 1-4.

483 2. Syrian observatory for Human Rights. More than 570 thousand people were killed on 484 the Syrian territory within 8 years of revolution demanding freedom, democracy, justice, and 485 equality. 2019. http://www.syriahr.com/en/?p=120851. Accessed on 29 Occtober 2019.

486 3. Wise PH. The epidemiologic challenge to the conduct of just war: confronting indirect 487 civilian casualties of war. Daedalus 2017; 146(1): 139-54.

488 4. Alda E, Mc Evoy C. Beyond the Battlefield: Towards a Better Assessment of the 489 Human Cost of Armed Conflict: Small Arms Survey; 2017.

490 5. Rubenstein L, Bales C, Spitzer W, Wille C. Violence on the frontline: Attacks on 491 Health Care in 2017, 2019.

$492 \quad$ 6. UNHCR. Mid-year trends 2018. 2019.

493 https://www.unhcr.org/afr/statistics/unhcrstats/5c52ea084/mid-year-trends-2018.html 494 (accessed 15 March 2019).

495 7. Bendavid E, Boerma T, Akseer N, et al. The health effects of armed conflict on 496 women, chidren and adolescents. The Lancet 2021 (in press).

4978 8. Peterson K. From the field: gender issues in disaster response and recovery. Natural

498 Hazards Observer, Special Issue on Women and Disasters 1997; 21(5).

499 9. Wise PH, Shiel A, Southard N, et al. The political and security dimensions of the 500 humanitarian health response to violent conflict. The Lancet 2021 (in press).

501 10. Guha-Sapir D, Schlüter B, Rodriguez-Llanes JM, Lillywhite L, Hicks MH-R. Patterns 502 of civilian and child deaths due to war-related violence in Syria: a comparative analysis from 503 the Violation Documentation Center dataset, 2011-16. The Lancet Global Health 2018; 6(1): 504 e103-e10.

505 11. Shield R. The Saudi air war in Yemen: A case for coercive success through battlefield 506 denial. Journal of Strategic Studies 2018; 41(3): 461-89.

507 12. Chaudhri S, Cordes K, Miller N. Humanitarian health programming and monitoring in 508 inaccessible conflict settings: a literature review. Journal of International Humanitarian 509 Action 2019; 4(1): 9.

$510 \quad$ 13. World Bank. Total population database.

511 https://data.worldbank.org/indicator/sp.pop.totl (accessed 30 April 2020).

512 14. United Nations Office for the Coordination of Humanitarian Affairs (OCHA). Global 513 Humanitarian Overview 2020. Accessed on 30 April 2020 2019: Available from:

514 https://www.unocha.org/global-humanitarian-overview-2020.

$515 \quad$ 15. Irin News. Who's who: South Sudan's splintering war. 2018.

516 https://www.irinnews.org/analysis/2018/04/12/who-s-who-south-sudan-s-splintering-civil-war 517 (accessed 15 March 2019).

518 16. Mirzazada S, Padhani ZA, Jabeen S, et al. Impact of conflict on maternal and child 519 health service delivery: a country case study of Afghanistan. Conflict and Health 2020; 14(1): 520 1-13. 
17. Das JK, Padhani ZA, Jabeen S, et al. Impact of conflict on maternal and child health service delivery-how and how not: a country case study of conflict affected areas of Pakistan. Conflict and Health 2020; 14: 1-16.

18. Ramos Jaraba SM, Quiceno Toro N, Ochoa Sierra M, et al. Health in conflict and post-conflict settings: reproductive, maternal and child health in Colombia. Conflict and Health 2020; 14: 1-21.

19. Altare C, Malembaka EB, Tosha M, et al. Health services for women, children and adolescents in conflict affected settings: experience from North and South Kivu, Democratic Republic of Congo. Conflict and health 2020; 14: 1-19.

20. Ahmed Z, Ataullahjan A, Gaffey MF, et al. Understanding the factors affecting the humanitarian health and nutrition response for women and children in Somalia since 2000: a case study. Conflict and Health 2020; 14: 1-15.

21. Sami S, Mayai A, Sheehy G, et al. Maternal and child health service delivery in conflict-affected settings: a case study example from Upper Nile and Unity states, South Sudan. Conflict and Health 2020; 14: 1-12.

22. Abuja N. National Population Commission and ICF Macro; 2009. National Population Commission (NPC) [Nigeria] and ICF Macro Nigeria Demographic and Health Survey 2008.

23. Hurst SA, Mezger N, Mauron A. Allocating resources in humanitarian medicine. Public Health Ethics 2009; 2(1): 89-99.

24. Islamic Republic of Afghanistan Ministry of Public Health. Integrated Package of Essential Health Services. Available at: https://wwwlshtmacuk/sites/default/files/201909/IPHES_2019pdf 2019; Accessed on 22 November 2019.

25. World Health Organization. Monitoring the Building Blocks of Health Systems: A handbook of Indicators and their Measurement Strategies. Geneva: WHO, 2010.

26. Akik C, Semaan A, Shaker-Berbari L, et al. Responding to health needs of women, children and adolescents within Syria during conflict: intervention coverage, challenges and adaptations. Conflict and Health 2020; 14(1): 1-19.

27. Tappis H, Elaraby S, Elnakib S, et al. Reproductive, maternal, newborn and child health service delivery during conflict in Yemen: a case study. Conflict and health 2020; 14: $1-16$.

28. Ataullahjan A, Gaffey MF, Tounkara M, et al. C'est vraiment compliqué: a case study on the delivery of maternal and child health and nutrition interventions in the conflict-affected regions of Mali. Conflict and Health 2020; 14: 1-17.

29. Inter-Agency Working Group on Reproductive Health in Crises (IAWG). InterAgency FIeld Manual on Reproductive Health In Humanitarian Settings. 2018.

30. Save the Children, WHO, UNICEF. Newborn Health in Humanitarian Settings: Field guide. 2017.

https://resourcecentre.savethechildren.net/sites/default/files/documents/newbornhealthbookproduction2017-v4b-press.pdf (accessed 12 March 2019). 